\title{
High-Conductance Channel Formation in Yeast Mitochondria is Mediated by F-ATP Synthase e and g Subunits
}

\author{
Michela Carraro ${ }^{\mathrm{a}, \mathrm{b}}$ Vanessa Checchetto ${ }^{c}$ Geppo Sartoria Roza Kucharczyk ${ }^{\mathrm{d}}$ \\ Jean-Paul di Rago ${ }^{e}$ Giovanni Minervinia Cinzia Franchin ${ }^{a, f} \quad$ Giorgio Arrigonia,f \\ Valentina Giorgio ${ }^{a, b} \quad$ Valeria Petronillia,b Silvio C.E. Tosatto ${ }^{a} \quad$ Giovanna Lippe ${ }^{a}$ \\ Ildikó Szabób,c Paolo Bernardia,b
}

\begin{abstract}
aDepartment of Biomedical Sciences, University of Padova, Padova, ${ }^{b}$ Consiglio Nazionale delle Ricerche, Institute of Neuroscience, Padova, 'Department of Biology, University of Padova, Padova, Italy, 'Institute of Biochemistry and Biophysics, Polish Academy of Sciences, Warsaw, Poland, eInstitut de Biochimie et Génétique Cellulaires and CNRS, UMR 5095, Université de Bordeaux, Bordeaux, France, fProteomics Center, University of Padova and Azienda Ospedaliera di Padova, Padova 'Department of Food, Environmental and Animal Sciences, University of Udine, Udine, Italy
\end{abstract}

\section{Key Words}

Yeast mitochondria - Mitochondrial megachannel - Permeability transition - F-ATP synthase - Calcium

\begin{abstract}
Background/Aims: The permeability transition pore (PTP) is an unselective, $\mathrm{Ca}^{2+}$-dependent high conductance channel of the inner mitochondrial membrane whose molecular identity has long remained a mystery. The most recent hypothesis is that pore formation involves the F-ATP synthase, which consistently generates $\mathrm{Ca}^{2+}$-activated channels. Available structures do not display obvious features that can accommodate a channel; thus, how the pore can form and whether its activity can be entirely assigned to F-ATP synthase is the matter of debate. In this study, we investigated the role of F-ATP synthase subunits $e, g$ and $b$ in PTP formation. Methods: Yeast null mutants for $\mathrm{g} g$ and the first transmembrane (TM) $\alpha$-helix of subunit b were generated and evaluated for mitochondrial morphology (electron microscopy), membrane potential (Rhodamine123 fluorescence) and respiration (Clark electrode). Homoplasmic C23S mutant of subunit a was generated by in vitro mutagenesis followed by biolistic transformation. F-ATP synthase assembly was evaluated by BN-PAGE analysis. $\mathrm{Cu}^{2+}$ treatment was used to induce the formation of F-ATP synthase dimers in the absence of e and $g$ subunits. The electrophysiological properties of F-ATP synthase were assessed in planar lipid bilayers. Results: Null mutants for the subunits e and $\mathrm{g}$ display dimer formation upon $\mathrm{Cu}^{2+}$ treatment and show PTP-dependent mitochondrial $\mathrm{Ca}^{2+}$ release but not swelling. $\mathrm{Cu}^{2+}$ treatment causes

M. Carraro and V. Checchetto contributed equally to this work.

\begin{tabular}{ll}
\hline Paolo Bernardi, MD & Department of Biomedical Sciences, University of Padova \\
and Ildiko Szabò, PhD & Padova (Italy) \\
& E-Mail bernardi@bio.unipd.it; ildiko.szabo@unipd.it
\end{tabular}
\end{abstract}




\section{Cellular Physiology Cell Physiol Biochem 2018;50:1840-1855

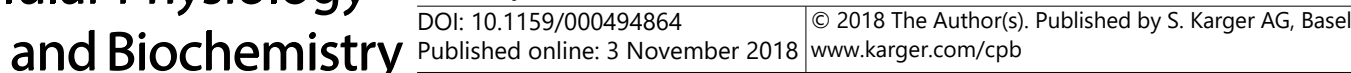 \\ Carraro et al.: Channel Formation by F-ATP Synthase e and g Subunits}

formation of disulfide bridges between Cys23 of subunits a that stabilize dimers in absence of $e$ and $g$ subunits and favors the open state of wild-type F-ATP synthase channels. Absence of $e$ and $g$ subunits decreases conductance of the F-ATP synthase channel about tenfold. Ablation of the first TM of subunit $b$, which creates a distinct lateral domain with e and $g$, further affected channel activity. Conclusion: F-ATP synthase $e, g$ and $b$ subunits create a domain within the membrane that is critical for the generation of the high-conductance channel, thus is a prime candidate for PTP formation. Subunits e and $g$ are only present in eukaryotes and may have evolved to confer this novel function to F-ATP synthase.

(C) 2018 The Author(s)

Published by S. Karger AG, Basel

\section{Introduction}

The permeability transition is a $\mathrm{Ca}^{2+}$-dependent increase of the mitochondrial inner membrane permeability to solutes with an exclusion limit of about 1,500 Da. This event is due to opening of the permeability transition pore (PTP), also called mitochondrial megachannel (MMC), an unselective high-conductance channel whose molecular identity is still the matter of debate [1]. It has recently been proposed that PTP formation involves the F-ATP synthase, which consistently generates $\mathrm{Ca}^{2+}$-activated channels in mitochondria from bovine hearts [2], human cells [3], yeast [4] and Drosophila [5]. The channel generated by F-ATP synthase is characterized by a variety of conductances. In mammals a state of about $500 \mathrm{pS}$ predominates [2,3], while the main conductance is $250-300 \mathrm{pS}$ in yeast [4] and 50 pS in Drosophila [5]. This latter finding matches previous results showing that Drosophila PTP is a $\mathrm{Ca}^{2+}$-induced $\mathrm{Ca}^{2+}$ release pathway rather than an unselective megachannel. The electrophysiological features of the mammalian F-ATP synthase channel are close to those of the bona fide MMC measured in intact inner membranes [6]. Depending on open time and channel size, PTP/MMC activity can contribute to $\mathrm{Ca}^{2+}$ homeostasis (short-term and/ or low conductance openings) or cell death (long-lasting high conductance openings) [1], but a molecular explanation for this complex behaviour has not been provided yet. Available structures of F-ATP synthase do not display obvious channel-like structural features [7-11] and therefore whether and how the enzyme can form the PTP remains debated. In spite of these open questions, the site of action of several PTP modulators is now being traced to specific residues of F-ATP synthase. Matrix $\mathrm{Ca}^{2+}$ is an essential permissive factor for opening of the PTP, which is then modulated by a large array of inducers (like SH oxidants and reagents) and inhibitors (like $\mathrm{Mg}^{2+}$, adenine nucleotides and matrix $\mathrm{H}^{+}$). Divalent metals $\left(\mathrm{Me}^{2+}\right)$ compete for a binding site that results in PTP opening when occupied by $\mathrm{Ca}^{2+}$ while all other tested $\mathrm{Me}^{2+}\left(\right.$ like $\mathrm{Mg}^{2+}, \mathrm{Mn}^{2+}, \mathrm{Sr}^{2+}, \mathrm{Ba}^{2+}$ ) are inhibitory $[12,13]$. This site appears to coincide with the catalytic core of F-ATP synthase, which coordinates $\mathrm{Mg}^{2+}$ and adenine nucleotides and discriminates between $\mathrm{Me}^{2+}$ through a conserved Thr residue on subunit $\beta$ [14]. The most potent inhibitors of the PTP are matrix $\mathrm{H}^{+}$, with channel block at $\mathrm{pH} 6.5$, and this effect depends on protonation of the unique His residue of OSCP subunit [15]. The involvement of F-ATP synthase in PTP formation is also supported by the effect of some specific enzyme interactors on the electrophysiological activity of the pore. For instance, among PTP inducers, Bz423 binds specifically the OSCP subunit of the enzyme [16] and consistently activates channel activity, whereas $\mathrm{ADP} / \mathrm{Mg}^{2+}$ and AMP-PNP, which bind the catalytic domain, inhibit channel opening [2]. Our working hypothesis is that the PTP forms from F-ATP synthase dimers (or higher order structures); and that a $\mathrm{Ca}^{2+}$-induced conformational change originating from the catalytic site is transmitted through OSCP and the peripheral stalk to the dimerization subunits e and g causing PTP opening within the inner membrane [17]. Consistently, genetic ablation of yeast subunits e and $\mathrm{g}$ causes desensitization of the pore to $\mathrm{Ca}^{2+}$ with increased resistance to opening $[4,18]$, yet whether these subunits directly contribute to channel formation remains unknown. Together with the first transmembrane (TM) $\alpha$-helix of subunit $b$, subunits e and g are located in a lateral domain close to the interface between monomers formed by adjacent subunits a [10]. Here, we investigate whether this domain contributes to generation of the PTP/MMC. 


\section{Cellular Physiology Cell Physiol Biochem 2018;50:1840-1855

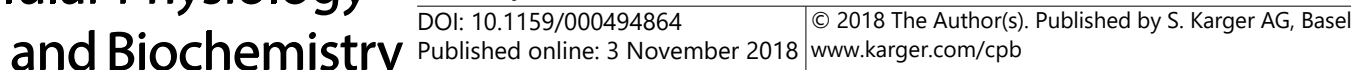 \\ Carraro et al.: Channel Formation by F-ATP Synthase e and g Subunits}

\section{Materials and Methods}

Materials and yeast strains

Digitonin, Alamethicin, ADP, FCCP, EDTA and EGTA were from Sigma (Milan, Italy) and ETH129 from Sigma Aldrich Japan. NADH, disodium salt was purchased from Roche. The S. cerevisiae strains BY4743 (4741/4742), W303 (MATa/MAT $\alpha$, leu2-3, 112 trp1-1 can1-100 ura3-1 ade2-1 his3-11, 15) as well as

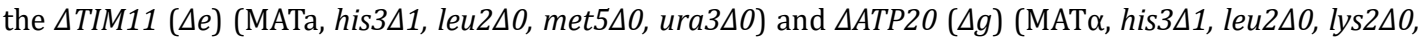
ura3 $\triangle 0$ ) were purchased from Thermo Scientific. TIM11 and ATP20 genes were replaced by KanMX cassette. $\triangle T I M 11 \triangle A T P 20(\Delta e \Delta g)$ mutants were obtained by mating the $\triangle T I M 11(\mathrm{e})$ and $\triangle A T P 20(\mathrm{~g})$ strains and selecting the diploids on SD ( $0.67 \%$ nitrogen base w/o amino acids, $2 \%$ dextrose) selective medium containing the required nutritional supplements except methionine and lysine. Diploids were then induced to sporulate in $1 \%$ potassium acetate, tetrads were dissected and haploids were analyzed with semi-quantitative PCR to detect null mutants for TIM11 (e) and ATP2O (g) genes. Deletion of ATP4 (b) gene has been carried out by substituting the genomic sequence with the His cassette of pFA6a-His3MX6 vector (for triple KO generation) or with Kan cassette of pFA6a-KanMX4 vector (for single KO generation) using following primers: FOR 5'AAGACTGACGAGAATTCAGTACCTCCTAAGTGCGCAAGAGATAAACA

GCTGAAGCTTCGTACGC and REV 5'-CTTTTCTTTCATTCTTGTCGCAGTTACTGTTGTGATTACTTCAATGCA TAGGCCACTAGTGGATCTG. Briefly, fresh liquid W303 or $\triangle T I M 11 \Delta A T P 20(\Delta e \Delta g)$ diploid cultures with an OD600 of about 0.6 were harvested, washed with sterile $\mathrm{H}_{2} \mathrm{O}$ and suspended in $100 \mathrm{mM}$ LiAc solution for 15 $\mathrm{min}$ at $30^{\circ} \mathrm{C}$. Then, cells were suspended in 25\% PEG 3350 (50\% w/v), $100 \mathrm{mM} \mathrm{LiAc,} 20 \mu \mathrm{g} / \mathrm{ml} \mathrm{DNA}$ carrier and $10 \mu \mathrm{l} \mathrm{PCR}$ product, incubated $30 \mathrm{~min}$ at $30^{\circ} \mathrm{C}$ and then $20 \mathrm{~min}$ at $42^{\circ} \mathrm{C}$. Cells were then grown for 3 hours in YP medium with $2 \%$ glucose, washed twice and finally plated on SD selection medium containing all nutrients except HIS or on rich medium supplemented with G418. Colonies were checked for the presence of the deletion using a semi-quantitative PCR and appropriate primers. For ATP4 (b) gene cloning, pFL38URA vector was digested with $\mathrm{KpnI}$ and BamHI and the target gene was amplified using primers that include upstream and downstream regulatory sites (endogenous promoter and termination sequence):

FOR 5'- CACGACGTTGTAAAACGACGGCCAGTGAATTCGAGCTCGGTACCCCTCTTCACCGCTCATTCGGA REV 5'TTACGCCAAGCTTGCATGCCTGCAGGTCGACTCTAGAGGATCCCCCAAACTGAACTCATAAGGCG. Cloned products were confirmed by sequence analysis. To delete the first TM domain (186-243 bp corresponding to Ile62-Ser81) of ATP4 (b) the InFusion HD Cloning Plus kit was used, with the following primers: Del FOR 5'- AATGAATTGTACGTTATCAACGATGAAAGTATTTTATTGC and Del REV 5'AACGTACAATTCATTATTATTACCTGGAATGGCATTGATG, according to manufacturer's instructions and products were confirmed by sequence analysis. $\triangle A T P 4(\Delta b)$ or $\triangle T I M 11 \Delta A T P 20 \triangle A T P 4(\Delta e \Delta g \Delta b)$ diploids were transformed with pFL38-URA vectors carrying the wild-type (b) or truncated (bD1TM) ATP4 gene, as described previously. Resulting clones were grown in 1\% potassium acetate medium for sporulation. Haploids were plated in selection agar media (YPD+G418, Drop-out -URA or -HIS) and properly selected. The generation of homoplasmic C23S mutant was carried out by in vitro mutagenesis followed by biolistic transformation into the mitochondria of atp6-C23S gene and its recombination into the ATP6 locus [19]. The QuikChange XL Site-directed Mutagenesis Kit of Stratagene and the following mutagenic oligonucleotides were used to introduce the mutation into the ATP6 gene sequence on pSDC8 plasmid (modified base in boldface):

\section{5'GGTTTACAATCATCATTTATTGATTTAAGTAGTTTAAATTTAACAACATTTTCATTATATAC3'}

and 5' GTATATAATGAAAATGTTGTTAAATTTAAACTACTTAAATCAATAAATGATGATTGTAAACC3'.

The mutated ATP6 fragment was released with BamHI-EcoRI digestion and ligated at the same sites with pJM2 [20]. This plasmid contains the yeast mitochondrial COX2 gene as a marker for mitochondrial transformation. The resulting pRK23 plasmid was introduced by co-transformation with the nuclear selectable LEU2 gene containing plasmid Yep351 into the $\mathrm{r}^{0}$ strain DFS160 by microprojectile bombardment using a biolistic PDS-1000/He particle delivery system (Bio-Rad) as described [21]. Mitochondrial transformants were identified among the $\mathrm{Leu}^{+}$nuclear transformants by their ability to produce respiring clones when mated to the non-respiring NB40-3C strain (MATa lys2 leu2-3, 112 ura3-52 his3DHinDIII arg8::hisG, rho ${ }^{+} \operatorname{cox} 2-62$ ) bearing a deletion in the mitochondrial COX2 gene. The resulting clones ( $\mathrm{r}^{-}$synthetic RKY53) were crossed to strain MR10 [22] with a WT nucleus and in which the ATP6 gene is replaced by ARG8m (atp6::ARG8m). In these crosses the atp6-C23S genes replaced by mtDNA recombination the ARG8m marker, resulting in a strain with complete $\left(\mathrm{r}^{+}\right)$mtDNA carrying the atp6-C23S mutation, RKY54. The presence of mutation was verified by DNA sequencing of the amplified atp6-C23S gene. 


\section{Cellular Physiology Cell Physiol Biochem 2018;50:1840-1855 and Biochemistry DOl: 10.1159/000494864 2018 (O) 2018 The Author(s). Published by S. Karger AG, Basel

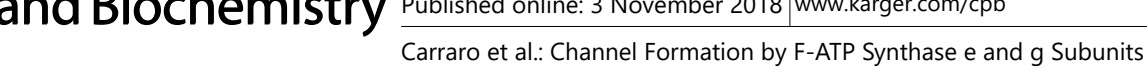

\section{Yeast culture and mitochondria isolation}

Yeast cell cultures in YPD (1\% yeast extract, 1\% bacto-polypeptone, and 2\% glucose) or Drop-outURA ( $2 \%$ glucose) media were used to generate a $400 \mathrm{ml}$ preculture of YP medium supplemented with $2 \%$ galactose with an initial OD600 of 0.2 and let incubate with rotation at $180 \mathrm{rpm}$ for $20 \mathrm{~h}$ at $30^{\circ} \mathrm{C}$, yielding about $4.0 \mathrm{~g}$ of yeast cells. Yeast mitochondria were isolated as described in [4].

\section{Measurement of oxygen consumption and membrane potential}

Mitochondrial oxygen consumption was measured with a Clark electrode (Yellow Springs Instruments, $\mathrm{OH}, \mathrm{USA}$ ) equipped with magnetic stirring and thermostatic control maintained at $25^{\circ} \mathrm{C}$. Five hundred micrograms of isolated mitochondria were incubated in $250 \mathrm{mM}$ Sucrose, $10 \mathrm{mM}$ Tris-MOPS, $10 \mathrm{mM}$ $\mathrm{Pi}, 30 \mu \mathrm{M}$ EGTA, pH 7.4 medium, $2 \mathrm{ml}$ final volume and $1 \mathrm{mM}$ NADH, $0.1 \mathrm{mM}$ ADP and $4 \mu \mathrm{M}$ FCCP were sequentially added. Mitochondrial membrane potential $(\Delta \Psi)$ was evaluated using the lipophilic positively charged fluorescent probe Rhodamine123, with a Fluoroskan Ascent FL (Thermo Electron) 96-well plate reader. Excitation and emission wavelengths were 503 and $523 \mathrm{~nm}$, respectively. One hundred micrograms of isolated mitochondria were suspended in $250 \mathrm{mM}$ Sucrose, $10 \mathrm{mM}$ Tris-MOPS, $2 \mathrm{mM} \mathrm{Pi,} 10 \mu \mathrm{M}$ EGTA, pH 7.4 medium, $0.2 \mathrm{ml}$ final volume, supplemented with $0.4 \mu \mathrm{M}$ Rhodamine 123 and $1 \mathrm{mM} \mathrm{NADH}$ and $2 \mu \mathrm{M}$ FCCP were added. $\Delta \Psi$ was estimated according to the Nernst equation considering Rhodamine123 fluorescence after the addition of NADH and of FCCP as endpoints.

\section{Mitochondrial calcium retention capacity and matrix swelling}

Extramitochondrial $\mathrm{Ca}^{2+}$ uptake was measured by Calcium Green-5N (Molecular Probes) fluorescence using a Fluoroskan Ascent FL (Thermo Electron) plate reader. One hundred micrograms of mitochondria were suspended in a slightly hypotonic sucrose medium (250 mM Sucrose, $10 \mathrm{mM}$ Tris-MOPS and $10 \mu \mathrm{M}$ EGTA), supplemented with $0.5 \mathrm{mg} / \mathrm{ml}$ Bovine Serum Albumin (BSA), $1 \mathrm{mM} \mathrm{NADH,} 2 \mathrm{mM} \mathrm{Pi,} 5 \mu$ M ETH129 and $1 \mu \mathrm{M} \mathrm{Ca}^{2+}$ Green-5N probe. $\mathrm{Ca}^{2+}$ release assay was performed with a Perkin Elmer LS50B instrument in $2 \mathrm{ml}$ volume. Matrix swelling was evaluated by measuring optical density changes at $540 \mathrm{~nm}$ with the Cary 100 UV-Vis Spectrophotometer (Agilent Technologies). Five hundred micrograms of mitochondria were suspended in $250 \mathrm{mM}$ Sucrose, $10 \mathrm{mM}$ Tris-MOPS, $1 \mathrm{mM}$ Pi, $1 \mathrm{mM}$ NADH, $0.5 \mathrm{mg} / \mathrm{ml} \mathrm{BSA}, 5 \mu \mathrm{M}$ ETH129, 10 $\mu \mathrm{M}$ EGTA, at pH 7.4, final volume $2 \mathrm{ml}$. yPTP inducers were added as indicated in Figure legends.

\section{Gel electrophoresis and Western blotting}

For cross-linking experiments, mitochondria were treated as described in [4]. Bands corresponding to dimers of ATP synthase were cut from the gels and protein complexes were eluted overnight by incubation at $4^{\circ} \mathrm{C}$ in $25 \mathrm{mM}$ Tricine, $15 \mathrm{mM} \mathrm{MgSO}_{4}, 8 \mathrm{mM}$ ATP, $7.5 \mathrm{mM}$ Bis-Tris, $1 \%$ (w/v) n-heptyl $\beta$-D-thioglucopyranoside, $\mathrm{pH} 7.0$ Samples were then centrifuged at $20,000 \mathrm{x} g$ for $10 \mathrm{~min}$ at $4^{\circ} \mathrm{C}$ and supernatants were used for bilayer experiments. Dimers eluted from BN gels were also subjected to SDS-PAGE followed by silver staining. Western Blot analysis was performed in isolated mitochondria following standard procedures. Rabbit antibodies against yeast g, e, g and b F-ATP synthase subunits were a kind gift of Marie-France Giraud, CNRS and University of Bordeaux.

\section{Planar lipid bilayer}

Electrophysiology experiments were carried out using a Warner Instruments Incorporated planar bilayer apparatus. Bilayers were prepared using purified L- $\alpha$-Phosphatidylcholine in decane (Sigma-Aldrich) and $1 \%$ chloroform (Sigma-Aldrich) across a $250 \mu \mathrm{m}$ hole in a polystyrene cuvette (Warner Instruments). $\mathrm{L}-\alpha$-Phosphatidylcholine was purified by several cycles of precipitation with cold acetone from a chloroform solution. Bilayer membranes with approximately $150-200 \mathrm{pF}$ capacity were used for experiments. The lipid membrane divided the trans and cis compartments. All reported voltages refer to the cis chamber, zero being assigned to the trans (grounded) side. The bilayer set up was connected to the external circuit through salt bridges $(1 \mathrm{M} \mathrm{KCl})$ with $\mathrm{Ag} / \mathrm{AgCl}$ electrodes. Unitary currents were recorded using an Axon BC-525C patch clamp amplifier (Warner Instruments Incorporated). Recordings were filtered at $1 \mathrm{kHz}$, digitized at $300 \mathrm{KHz}$ and analyzed off-line with PClamp 8.1 and ORIGIN 6.0 software. Experiments were performed in $150 \mathrm{mM}$ $\mathrm{KCl}$ and $10 \mathrm{mM}$ HEPES ( $\mathrm{pH}=7.5$ ) unless otherwise specified. Isolated F-ATP synthase preparation was added to the cis compartment, while other additions are indicated in the Figure legends. All measurements were made at room temperature.

\section{KARGER}




\section{Cellular Physiology Cell Physiol Biochem 2018;50:1840-1855

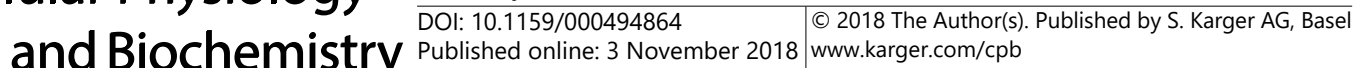 Carraro et al:. Channel Formation by F-ATP Synthase e and g Subunits}

\section{Electron microscopy samples}

Isolated mitochondria were processed for electron microscopy as described [23]. After inclusion, sample were dissected in $80 \mathrm{~nm}$ slices, treated with uranyl acetate and lead citrate and analyzed with FEI TecnaiG12 transmission electron microscope (Veleta camera, OSIS).

\section{Protein Digestion and Mass Spectrometry analysis}

BN-PAGE gel bands containing the monomeric and dimeric forms of ATP synthase isolated from the different yeast strains were digested with trypsin as described in [24]. Briefly, gel bands were cut into small pieces, and treated for $1 \mathrm{~h}$ at $56^{\circ} \mathrm{C}$ with $10 \mathrm{mM}$ dithiothreitol (Fluka) in $50 \mathrm{mM} \mathrm{N} \mathrm{NH}_{4} \mathrm{HCO}_{3}$. Cysteine residues were then alkylated for $45 \mathrm{~min}$ (room temperature and in the dark) using $55 \mathrm{mM}$ iodoacetamide (Sigma-Aldrich) in $50 \mathrm{mM} \mathrm{NH}_{4} \mathrm{HCO}_{3}$. In-gel protein digestion was performed at $37^{\circ} \mathrm{C}$, overnight with $30 \mu \mathrm{L}$ of sequencing-grade modified trypsin (Promega, $12.5 \mathrm{ng} / \mathrm{mL}$ in $50 \mathrm{mM} \mathrm{NH}_{4} \mathrm{HCO}_{3}$ ). Peptides were extracted from the gel with 3 changes of $50 \%(\mathrm{v} / \mathrm{v})$ acetonitrile $/ 0.1 \%(\mathrm{v} / \mathrm{v})$ formic acid, dried under vacuum, suspended in $0.1 \%(\mathrm{v} / \mathrm{v})$ formic acid and analyzed by liquid chromatography tandem mass spectrometry (LC-MS/MS). The analysis was carried out with an LTQ-Orbitrap XL mass spectrometer (Thermo Fisher Scientific) coupled with a nano-HPLC Ultimate 3000 (Dionex - Thermo Fisher Scientific). Peptide mixtures were separated at a flow rate of $250 \mathrm{~nL} / \mathrm{min}$ with a $11 \mathrm{~cm}$ pico-frit column packed in-house with C18 material (Aeris Peptide $3.6 \mu \mathrm{m}$ XB-C18; Phenomenex) and using a linear gradient of acetonitrile/ $0.1 \%$ formic acid from $3 \%$ to $40 \%$ in $40 \mathrm{~min}$. A data-dependent acquisition mode with a top-ten method (a full scan at 60, 000 resolution on the Orbitrap followed by MS/MS fragmentation in the linear ion trap of the ten most intense ions) was used to collect the MS and MS/MS spectra. Raw files were analyzed with the software package MaxQuant [25] and the search engine Andromeda [26]. Peptide search was done against the Yeast section of the Uniprot database (version 20150401, 6741 entries) and a database of common contaminants found in proteomics experiments. Trypsin was set as digesting enzyme, with carbamidomethylation of cysteine residues as fixed modification and methionine oxidation as variable modification. Results were filtered at a False Discovery Rate of 0.01 , both at the peptide and protein level. Intensity Based Absolute Quantification (iBAQ) values [27] were calculated by the software and used as an estimate of the molar quantity of the proteins.

\section{Sequence analysis}

Sequence conservation analysis was performed to highlight relevant conserved features of $S$. cerevisiae ATP synthase chains b, e and g. Their canonical sequences were retrieved from Uniprot [28] (accession codes: P05626, P81449, Q12233 for subunits b, e and g, respectively). Orthologues of F-ATP synthase subunits sequences of Homo sapiens, Mus musculus, Rattus norvegicus, Danio rerio, and Drosophila melanogaster were retrieved from the OMA browser [29] database and aligned with T-Coffee [30] using default parameters. The final alignment was visualized using Jalview [31]. Search onto PFAM5 [32] database was used to identify conserved domains. Secondary structure content was predicted with FELLS [33], while transmembrane domains were predicted with TMHMM [34]. The 3D structure of S. cerevisiae (PDB code: 6B2Z) was visualized with Chimera [35] and used to map chains position.

\section{Statistical analysis}

Data were expressed as mean \pm standard error of mean (SEM). To compare groups with normally distributed data, Student's t test or ANOVA followed by Bonferroni post hoc test were performed using the Prism 5.0 software (GraphPad) as specified in the Figure Legends. Differences with $P$ values of less than 0.05 are considered significant.

\section{Results}

Generation of yeast mutants lacking $e, g$ and the first TM domain of subunit $b$

A high-resolution structure of the yeast $\mathrm{F}_{\mathrm{o}}$ domain has been recently obtained [10] (Fig. 1A). Subunits e (green), g (orange) and the N-terminal first TM $\alpha$-helix of subunit b (blue) closely interact in a specific lateral domain, consistent with previous cross-linking studies [36-41]. The C-terminus of subunit b instead contacts OSCP. This arrangement contributes to connect the $\mathrm{F}_{1}$ and $\mathrm{F}_{\mathrm{o}}$ domains and makes subunit $\mathrm{b}$ an excellent candidate for transduction of pore-modulating signals that converge on $\operatorname{OSCP}\left(\right.$ e.g. $\mathrm{Ca}^{2+}$ and $\left.\mathrm{pH}\right)$ to the inner membrane, 
where the channel must form. Sequence alignment of subunits $b$ and of subunits e and $\mathrm{g}$, which are not present in prokaryotes, reveals a high degree of conservation. Subunit $\mathrm{b}$ displays a conserved short TM domain spanning residues Ile62-Ser81 (including the signal peptide) and a second TM domain with lower sequence identity (Fig. S1 - for all supplemental material see www.karger.com/10.1159/000494864). Subunit e possesses an N-terminal TM domain followed by a conserved coiled-coil segment with insertions in D. melanogaster and S. cerevisiae (Fig. S2). Subunit g is also highly conserved and displays a single TM domain at the C-terminus; like subunit e, it bears a GXXXG motif, which typically mediates proteinprotein interactions [38, 39] (Fig. S2). Because of these features, we suspected that subunits $\mathrm{e}, \mathrm{g}$ and the first TM $\alpha$-helix of b could contribute to formation of the PTP/MMC, which has only been detected in eukaryotes.

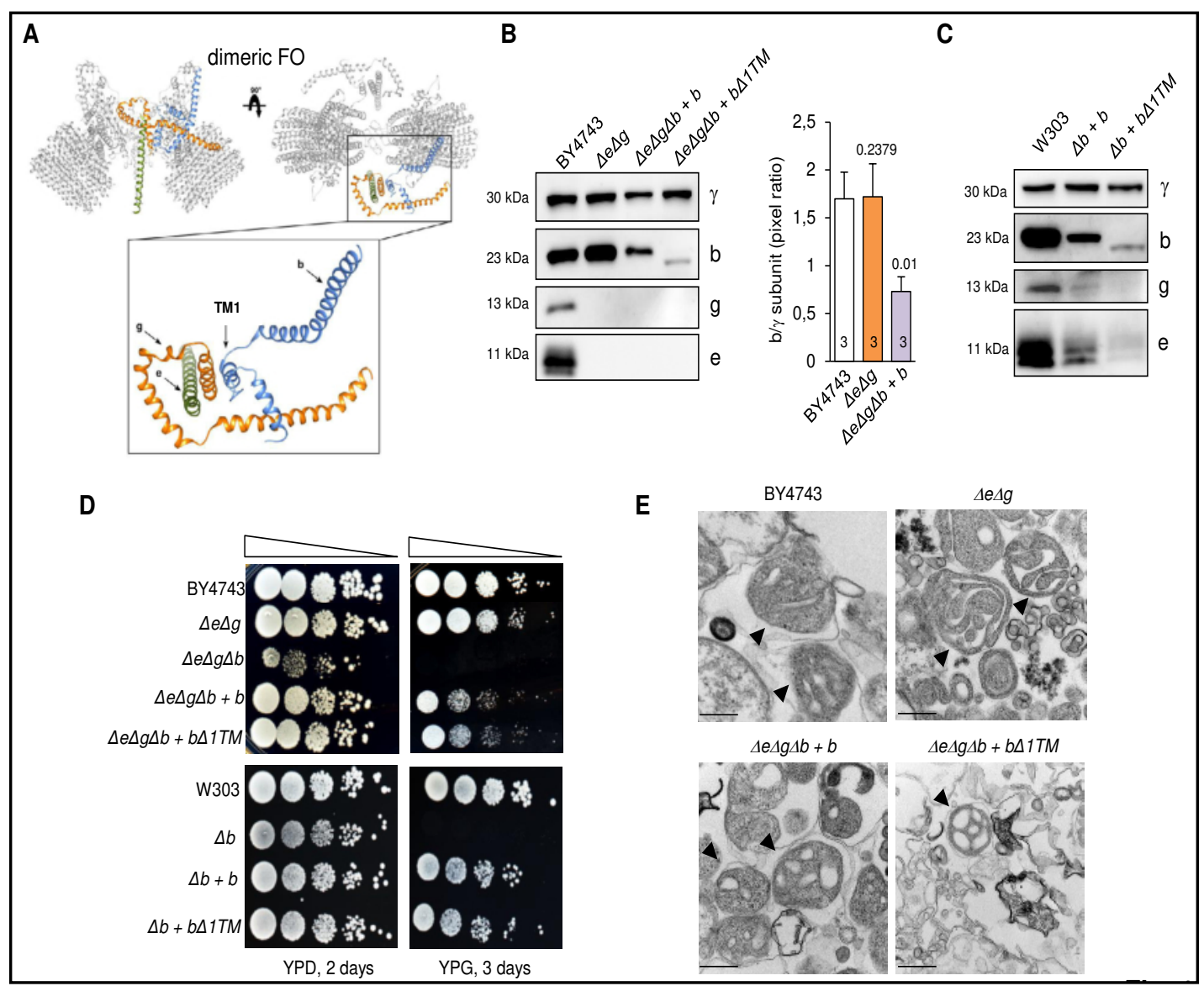

Fig. 1. Generation of yeast mutants lacking e/g subunits and the first transmembrane $\alpha$-helix of subunit b. (A) Location of e (green), g (orange) and b (blue) subunits within the dimeric $\mathrm{F}_{\mathrm{o}}$ complex of S. cerevisiae F-ATP synthase (deposited Cryo-EM map, EMD-7036), lateral (left) and top (right) views. Bottom, magnification of the lateral domain (TM1 indicates the first transmembrane $\alpha$-helix of subunit b). (B) Isolated mitochondria from BY4743, $\Delta \mathrm{e} \Delta \mathrm{g}, \Delta \mathrm{e} \Delta \mathrm{g} \Delta \mathrm{b}+\mathrm{b}$ and $\Delta \mathrm{e} \Delta \mathrm{g} \Delta \mathrm{b}+\mathrm{b} \Delta 1 \mathrm{TM}$ strains were evaluated by Western Blotting for $\gamma, \mathrm{b}, \mathrm{e}$ and $g$ subunits content, and the ratio between $b$ and $\gamma$ subunits is reported on the right. Data are mean \pm SEM of 3 independent experiments. * $\mathrm{P} \leq 0.05$ vs BY4743, calculated with the Student's t-test. Quantification of $\mathrm{b} \Delta 1 \mathrm{TM}$ is not reported because the antibody recognizes the first 83 amino acids, part of which are located in the deleted sequence. (C) Isolated mitochondria from $\mathrm{W} 303, \Delta \mathrm{b}+\mathrm{b}$ and $\Delta \mathrm{b}+\mathrm{b} \Delta 1 \mathrm{TM}$ strains were evaluated by Western Blotting for $\gamma, \mathrm{b}$, e and $\mathrm{g}$ subunits content. This is representative of 3 independent experiments. (D) Growth properties of yeast mutants. Fresh liquid glucose or selective medium cultures were kept to OD 1 , serially diluted, spotted onto glucose and glycerol plates, and incubated at $30^{\circ} \mathrm{C}$ for the indicated number of days. (E) Electron microscopy images from isolated mitochondria (black arrowheads) of the indicated genetic background. Scale bar, $500 \mathrm{~nm}$. 


\section{Cellular Physiology Cell Physiol Biochem 2018;50:1840-1855

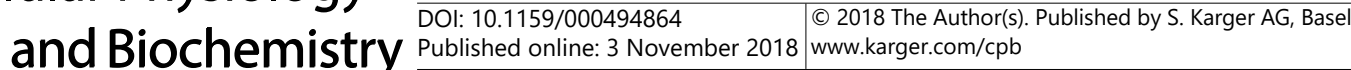 \\ Carraro et al.: Channel Formation by F-ATP Synthase e and g Subunits}

We generated $\Delta e \Delta g$ and $\Delta e \Delta g \Delta b$ yeast mutants, and re-expressed either wild-type or truncated b subunit lacking residues Ile62-Ser81 (bD1TM) (Fig. 1B). We could not assess the contribution of the first TM of subunit b per se because its ablation causes loss of subunit $\mathrm{g}$ [37] and reduction in subunit e protein level, with a consequent effect on F-ATP synthase dimerization (Fig. 1C). The role of subunit e per se was also not possible to assess since the lack of this protein leads to the loss of subunit g [42]. Both reexpressed wild-type and truncated b subunits could be detected (Fig. 1B); although the expression level was lower than that of the native b subunit (Fig. 1B), it did allow growth on galactose (Fig. S3A) and glycerol, while the b-null mutant had a petite phenotype (Fig. 1D). All mutants displayed the typical onion-like cristae morphology already reported for single e or g null mutants [43, 44] (Fig. 1E). Despite these alterations in cristae organization, the mitochondrial membrane potential was not substantially affected (Fig. S3B). All mutants displayed a decreased rate of respiration, while respiratory control ratios were comparable to wild-type mitochondria with the exception of the $b \Delta 1 T M$ mutants on a $\Delta e \Delta g$ background, which could not be stimulated by ADP or FCCP (Fig. S3C). Truncation of b subunit did not cause changes in the mitochondrial $\mathrm{Ca}^{2+}$ retention capacity (CRC, an indirect measure of the pore sensitivity to $\mathrm{Ca}^{2+}$ ) in addition to those already reported for the genetic ablation of subunits e and g [4] (Fig. S3D).

\section{$\mathrm{Cu}^{2+}$-mediated dimer formation in the absence of subunits $e$ and $g$ occurs through Cys23} of subunit a

All mutants described above assembled F-ATP synthase (Fig. 2A), even though at a lower extent, with 3:3:1:1 stoichiometry of $a, \beta, \gamma$ and b subunits, respectively (Fig. S4A) and expectedly [4] did not show dimers after extraction with digitonin (Fig. 2A). As in previous reports $[4,40,45]$, upon $\mathrm{Cu}^{2+}$ treatment $\Delta e \Delta g$ mutants formed dimers (Fig. 2A). Further truncation of subunit $\mathrm{b}$ decreased cross-linking efficiency, yet dimers formed and could be identified by activity staining (Fig. 2A). SDS-PAGE analysis of $\mathrm{Cu}^{2+}$-mediated dimers in $\Delta e \Delta g$ mutants revealed a slight reduction in total protein content but not major alterations in subunit composition (Fig. $2 \mathrm{~B}$ and Fig. S4B). The $\Delta e \Delta g \Delta b+b \Delta 1 T M$ mutant displayed a similar subunit pattern in monomers (Fig. 2B and S4A), while some small subunits were not detected in the preparation from $\mathrm{Cu}^{2+}$-mediated dimers (Fig. 2B and S4B).

$\mathrm{Cu}^{2+}$ has been widely used to investigate thiol-mediated protein-protein interactions and organization of yeast F-ATP synthase. Biochemical studies suggested that homodimers form at subunit a via its unique Cys23 [45]. In the recent $\mathrm{F}_{0}$ map, Cys23 residues of adjacent subunits face one another at an estimated distance of $22 \AA$ (Fig. 2C), which may appear too far for generating a disulfide bridge. However, the secondary structure of the N-terminus of subunit a (containing Cys23) suggests that it may be flexible and thus allow convergence within the minimal distance required for disulfide bond formation. This would be consistent with the observation that $\mathrm{Cu}^{2+}$-induced a-a dimers form at room temperature but not on ice [45]. In keeping with these findings, a $\Delta e$ strain carrying a homoplasmic C23S mutation on subunit a no longer formed dimers after treatment with $\mathrm{Cu}^{2+}$ even at low detergent concentrations (Fig. 2D), providing genetic evidence that Cys23 is responsible for $\mathrm{Cu}^{2+}$ dependent dimer formation. The C23S mutation did not affect mitochondrial CRC (Fig. 2E), while deletion of e subunit in the C23S mutant desensitized the PTP (as indicated by the doubled CRC) as already reported for the $\Delta e$ strain [4]. Thus, it is possible to study the channel activity of dimers lacking subunits e and $\mathrm{g}$ after their stabilization with $\mathrm{Cu}^{2+}$-induced disulfide bridges at Cys23 of subunit a.

\section{PTP size is affected by deletion of e and $g$ subunits}

We have previously shown that absence of e and $g$ subunits decreases the $\mathrm{Ca}^{2+}$-sensitivity of yeast PTP [4], probably because of the reduction in dimer content and thus in the number of possible PTP-forming units. Since pore size is affected by lack of lateral stalk subunits [46] we analyzed PTP-dependent swelling in mitochondria devoid of e and g subunits. We loaded mitochondria with a $\mathrm{Ca}^{2+}$ bolus of the same size and triggered PTP opening with the $\mathrm{SH}$ reagent copper-o-phenantroline $\mathrm{Cu}(\mathrm{OP})_{2}$ after completion of $\mathrm{Ca}^{2+}$ uptake (which occurs 


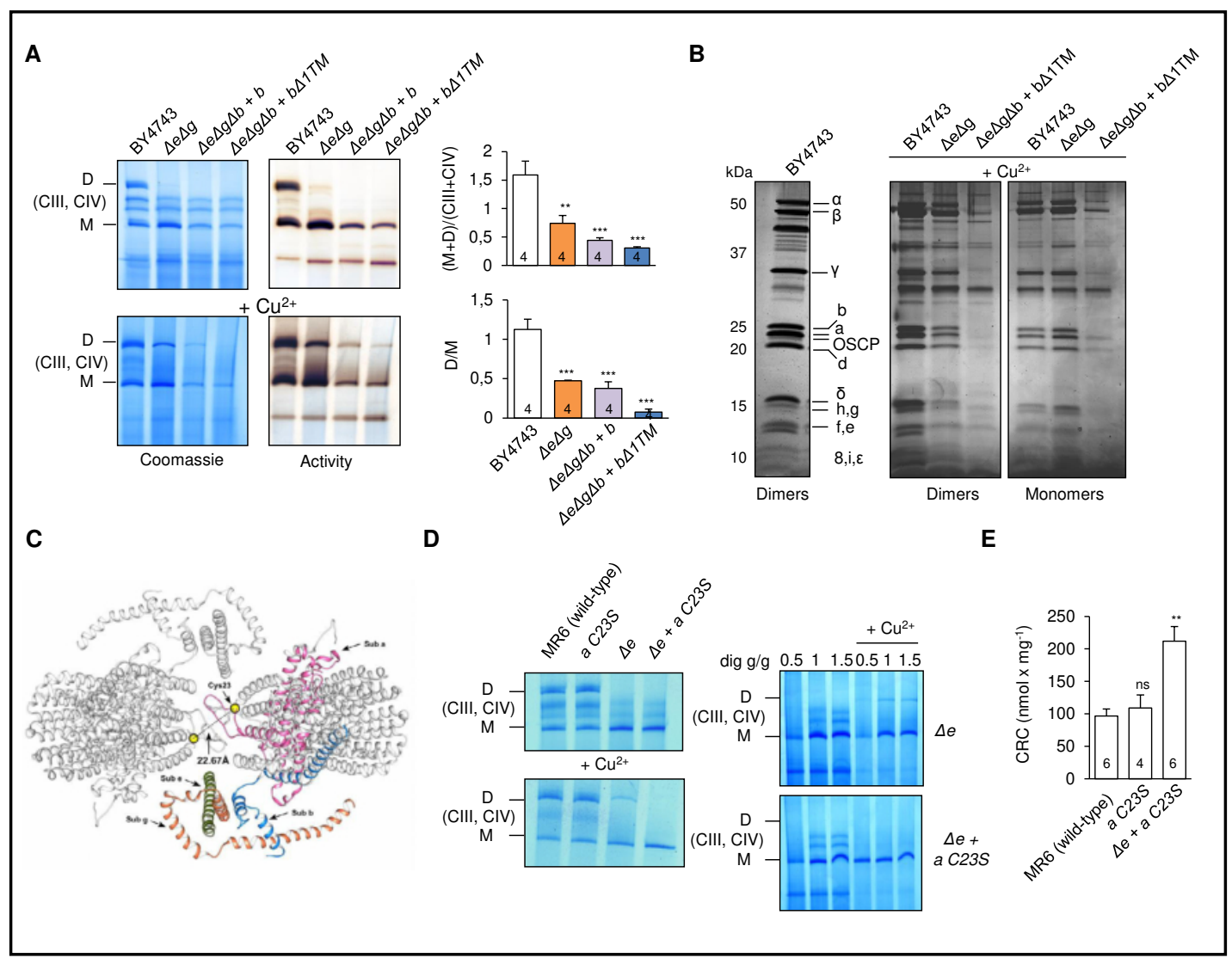

Fig. 2. $\mathrm{Cu}^{2+}$-mediated formation of F-ATP synthase dimers through oxidation of subunit a Cys23. (A) Five hundred micrograms of isolated mitochondria were extracted with $1.5 \mathrm{~g} / \mathrm{g}$ digitonin and subjected to BNPAGE to separate dimers (D) and monomers (M), which were identified by Coomassie blue or in-gel activity for ATP hydrolysis staining. Where indicated $\left(+\mathrm{Cu}^{2+}\right)$ mitochondria were pretreated with $2 \mathrm{mM} \mathrm{Cu}^{2+}$ prior to extraction (representative gels of 4 independent experiments). The top histogram reports the densitometric analysis of Coomassie-stained bands of monomers, dimers, CIII and CIV without $\mathrm{Cu}^{2+}$ treatment, and values on the ordinate refer to assembled F-ATP synthase (M+D) normalized to the (CIII+CIV) content. The bottom histogram reports the densitometric analysis of activity-stained bands of dimers and monomers obtained upon $\mathrm{Cu}^{2+}$ treatment, and values on the ordinate refer to the $\mathrm{D} / \mathrm{M}$ ratio. ${ }^{* *} \mathrm{P} \leq 0.005$ and ${ }^{* * *} \mathrm{P} \leq 0.001$ vs BY4743, by One-Way ANOVA with Bonferroni correction. (B) F-ATP synthase dimers eluted from BN-PAGE were resolved by SDS-PAGE and silver staining. Where indicated mitochondria had been treated with $\mathrm{Cu}^{2+}$, and the gel is representative of 3 independent experiments. (C) Structure of dimeric $\mathrm{F}_{0}$ complex highlighting the e (green), $g$ (orange), b (blue) and a (pink) subunits. Yellow dots highlight the unique Cys23 of subunits a and their estimated distance. (D) Mitochondria from indicated genotype were pretreated with $\mathrm{Cu}^{2+}$, subjected to BN-PAGE and stained with Coomassie (representative gel of 3 independent experiments). Right panel, digitonin titration after $\mathrm{Cu}^{2+}$ treatment for $\Delta \mathrm{e}$ and $\Delta \mathrm{e}+\mathrm{a} \mathrm{C} 23 \mathrm{~S}$ mutant mitochondria. (E) Mitochondrial $\mathrm{Ca}^{2+}$ uptake and its release due to yPTP opening were evaluated by a Calcium Retention Capacity (CRC) assay. One hundred micrograms of mitochondria were suspended in $250 \mathrm{mM}$ sucrose, $10 \mathrm{mM}$ MOPS-Tris and 10 $\mu$ M EGTA, pH 7.4, supplemented with $0.5 \mathrm{mg} / \mathrm{ml} \mathrm{BSA,} 2 \mathrm{mM} \mathrm{Pi}, 1 \mathrm{mM}$ NADH, $5 \mu$ M of ETH129 and $1 \mu \mathrm{M} \mathrm{Ca}^{2+}$ Green-5N probe. Values are expressed as $\mathrm{nmol} \mathrm{Ca}{ }^{2+} / \mathrm{mg}$ protein and histograms refer to the mean $\pm \mathrm{SEM}$ of indicated number of independent experiments. ${ }^{* *} \mathrm{P} \leq 0.005$ vs MR6, by One-Way ANOVA with Bonferroni correction.

via the ionophore ETH129). $\mathrm{Ca}^{2+}$ release readily ensued, and its rate was not substantially affected in any of the mutants (Fig. 3A). Remarkably, however, fast swelling linked to matrix sucrose diffusion only took place in the wild-type mitochondria, while swelling was minimal in the e and g nulls, with no further effect of the truncation of subunit b (Fig. 3B). It should 
be noted that swelling readily followed the addition of the pore-forming Alamethicin even in the mutants (Fig. 3B). This observation is important because it demonstrates that lack of swelling cannot be explained by ultrastructural differences in cristae and matrix morphology. As recently noted [47] these data are reminiscent of the effects of deletion of subunits $b$ and OSCP in human cells [46] and suggest that the size of the channel resulting from deletion of the dimerization subunits is close to the exclusion limit of sucrose. Consistently, electron microscopy images revealed that mitochondria of $\Delta e \Delta g$ mutants still possess a dense matrix after PTP opening, while swelling occurred after the addition of Alamethicin (Fig.

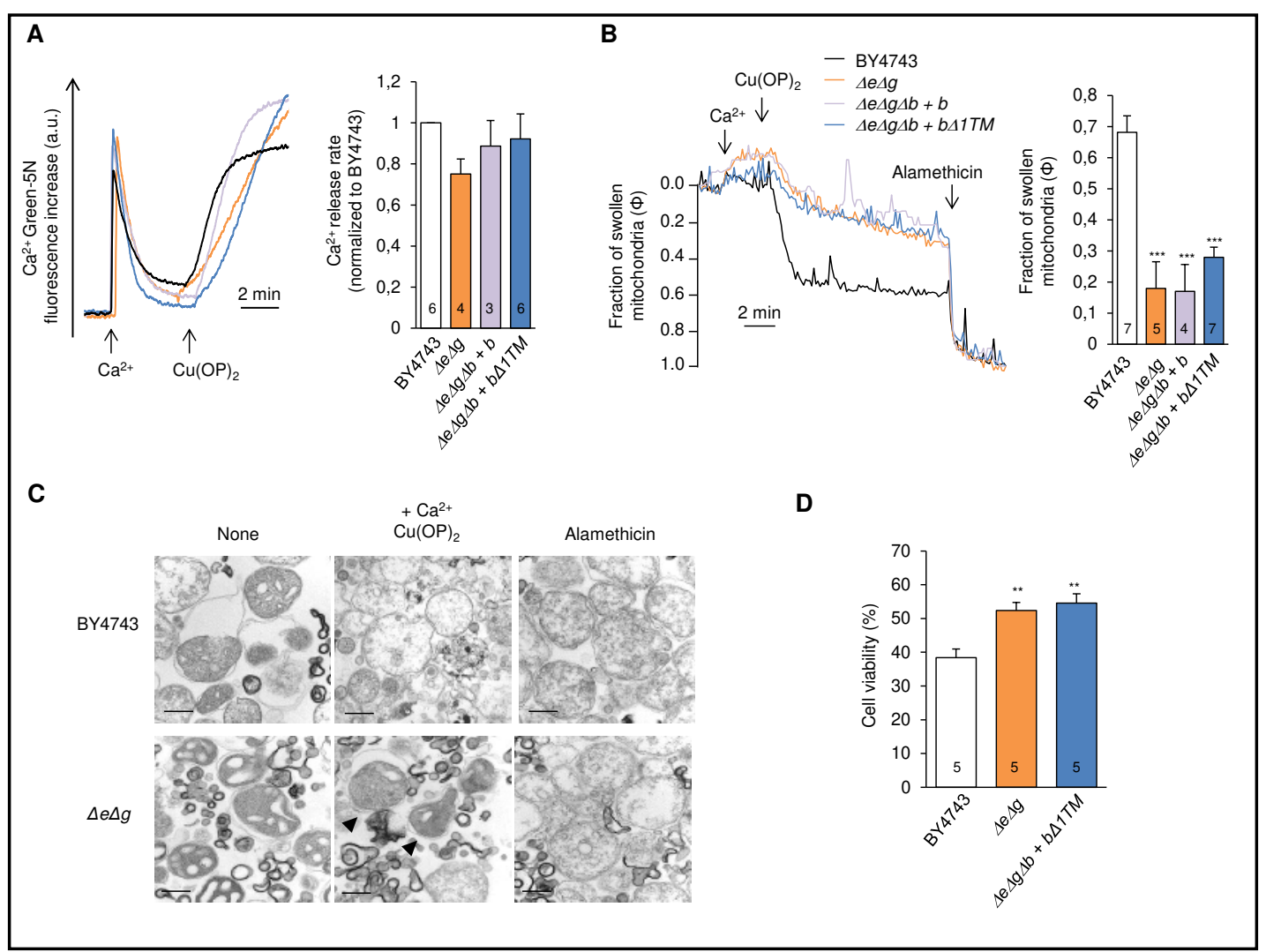

Fig. 3. Effect of subunit e and g deletion on mitochondrial PTP-dependent $\mathrm{Ca}^{2+}$ release and swelling. (A) Five hundred micrograms of mitochondria were suspended in $250 \mathrm{mM}$ sucrose, $10 \mathrm{mM}$ MOPS-Tris and 10 $\mu \mathrm{M}$ EGTA, pH 7.4, supplemented with $0.5 \mathrm{mg} / \mathrm{ml} \mathrm{BSA,} 1 \mathrm{mM} \mathrm{Pi}, 1 \mathrm{mM}$ NADH, $5 \mu \mathrm{M}$ ETH129 and $1 \mu \mathrm{M} \mathrm{Ca}^{2+}$ Green-5N. Where indicated $20 \mu \mathrm{M} \mathrm{Ca}^{2+}, 5 \mu \mathrm{M} \mathrm{Cu}(\mathrm{OP})_{2}$ were added. Traces are representative of indicated number of independent experiments, and the histogram refers to the rate of $\mathrm{Ca}^{2+}$ release normalized to the rate of the wild-type strain BY4743. No significant differences compared to BY4743 revealed by One-Way ANOVA test with Bonferroni correction. (B) Conditions were as in panel a except that $\mathrm{Ca}^{2+} \mathrm{Green}-5 \mathrm{~N}$ was omitted. Swelling was measured as the decrease of absorbance at $540 \mathrm{~nm}$. Where indicated $20 \mu \mathrm{M} \mathrm{Ca}^{2+}, 5$ $\mu \mathrm{M} \mathrm{Cu}(\mathrm{OP})_{2}$ and $10 \mu \mathrm{M}$ Alamethicin were added. The fraction of swollen mitochondria after PTP opening was calculated using maximal swelling induced by Alamethicin as 1 . Traces are representative of at least 5 independent experiments, and the histogram refers to the fraction of swollen mitochondria after completion of the process $12 \mathrm{~min}$ after $\mathrm{Cu}(\mathrm{OP})_{2}$, Data are mean $\pm \mathrm{SEM}$ of indicated number of independent experiments. *** $\mathrm{P} \leq 0.001$ vs BY4743 by One-Way ANOVA with Bonferroni correction. (C) Electron microscopy images of isolated mitochondria without any addition (untreated), after PTP opening induced by $\mathrm{Ca}^{2+}$ and $\mathrm{Cu}(\mathrm{OP})_{2}$ and after addition of Alamethicin. Scale bar, $500 \mathrm{~nm}$. (D) Cell viability in presence of high $\mathrm{Ca}^{2+}$ dose. Fresh liquid glucose or selective medium cultures were kept to OD 0.1 and let growing in YPGal liquid medium supplemented with $0.25 \mathrm{M} \mathrm{Ca}^{2+}$ at $30^{\circ} \mathrm{C}$ and absorbance at $600 \mathrm{~nm}$ was checked after 8 hours. Bars refer to percentage of OD600 of cultures in presence of $\mathrm{Ca}^{2+}$ compared to untreated ones. Data are mean \pm SEM of 5 independent experiments. ${ }^{* *} \mathrm{P} \leq 0.005$ vs BY4743 by One-Way ANOVA with Bonferroni correction. 


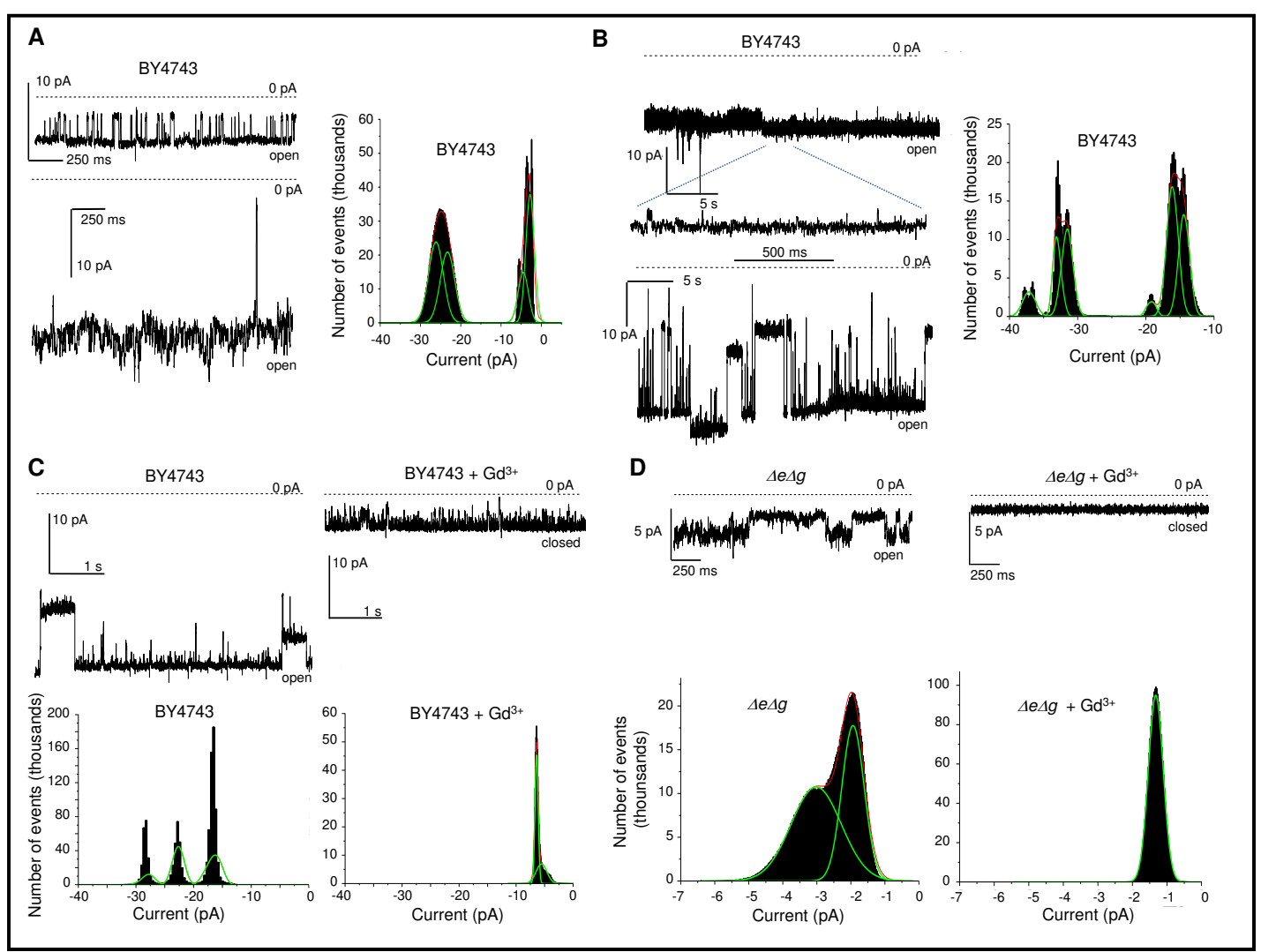

Fig. 4. F-ATP synthase channel activity of BY4743 and $\Delta \mathrm{e} \Delta \mathrm{g}$ dimers. In panels (A-D) $3 \mathrm{mM} \mathrm{Ca}^{2+}$ was added to the trans side, and $100 \mu \mathrm{M}$ phenylarsine oxide and $5 \mu \mathrm{M} \mathrm{Cu}(\mathrm{OP})_{2}$ to both the cis and trans side of the membrane. The concentration of $\mathrm{KCl}$ was $150 \mathrm{mM}$. (A, B) Representative current traces of F-ATP synthase dimers isolated from BY4743 yeast mitochondria treated with $2 \mathrm{mM} \mathrm{Cu}^{2+}$ prior to extraction. High $(280 \mathrm{pS})$ and low ( $35 \mathrm{pS}$ ) conductance states and amplitude histograms from $\geq 30 \mathrm{~s}$-long traces from two different experiments are shown. A: Vcis -80 mV; B: Vcis -60 mV. (C) Inhibition of wild-type F-ATP synthase channel by $1 \mathrm{mM} \mathrm{Gd}^{3+}(\mathrm{n}=3)$. Amplitude histograms obtained from 30s-long traces before (left panel) and after (right panel) addition of $\mathrm{Gd}^{3+}$ are shown. Vcis $-40 \mathrm{mV}$. (D) Channel activity of $\Delta \mathrm{e} \Delta \mathrm{g}$ F-ATP synthase dimers in the absence (upper trace, left) or presence (upper trace, right) of $1 \mathrm{mM} \mathrm{Gd}^{3+}(\mathrm{n}=6)$. Amplitude histograms from the same experiment are shown below the representative current traces. Vcis $-80 \mathrm{mV}$.

3C). Whether the PTP is involved in yeast cell death is still a matter of debate, although this process shares many features with the apoptotic pathway of mammalian cells [48]. Interestingly, the $\Delta e \Delta g$ and $\Delta e \Delta g \Delta b+b \Delta 1 T M$ mutants were measurably more resistant than the wild-type strain to $\mathrm{Ca}^{2+}$-dependent inhibition of growth (Fig. 3D), suggesting that the decreased capacity to undergo matrix swelling upon PTP opening might result in increased resistance to cell death.

\section{F-ATP synthase channel conductance is decreased in the absence of e and $g$ subunits}

We next assessed channel activity in planar lipid bilayers, a technique that allows measurement of single channel currents upon incorporation of gel-purified proteins [49]. After treatment of mitochondria with $\mathrm{Cu}^{2+}$, slices containing dimers were excised from the BN-PAGE gels, proteins were eluted as described [49] and analyzed as in previous studies $[2,4]$. In 19 successful trials with F-ATP synthase deriving from 5 different preparations from wild-type mitochondria, we observed single channel activity displaying both low- and high-conductance states (Fig. 4A and B). Compared to wild-type naive preparations [4], $\mathrm{Cu}^{2+}$ treatment stabilized the current in high-conducting states and increased the mean open time of the channel (Fig. S5A). The maximal conductance in $150 \mathrm{mM} \mathrm{KCl}$ was $300 \mathrm{pS}$ 
(representative traces in Fig. 4A-C and Fig. S5A). Mean maximal single channel conductance was $264.0 \pm 22.7 \mathrm{pS}(\mathrm{n}=11$, sem $)$, which is in the range of the naive channel that had not been pretreated with $\mathrm{Cu}^{2+}[4]$. Note that the channel also adopted a state of smaller amplitude, yielding conductances of $35 \mathrm{pS}$ (Fig. 4A) and $40 \mathrm{pS}$ (Fig. 4B). Finally, the high-conductance channel was inhibited by $1 \mathrm{mM} \mathrm{Gd}^{3+}$ (Fig. 4C), a general inhibitor of cation channels able to block also the bona fide PTP/MMC activity in patch clamp recordings of mitoplasts from mammalian cells (Fig. S5B).

A striking difference became apparent when preparations from $\Delta e \Delta g$ and $\Delta e \Delta g \Delta b+$ $b \Delta 1 T M$ strains were investigated under the same conditions. The $\Delta e \Delta g$ channel conductance never exceeded $55 \mathrm{pS}$ in $150 \mathrm{mM} \mathrm{KCl}$, with mean maximal conductance of $30.6 \pm 3.2 \mathrm{pS}$ (representative current traces and amplitude histograms from the same experiment are

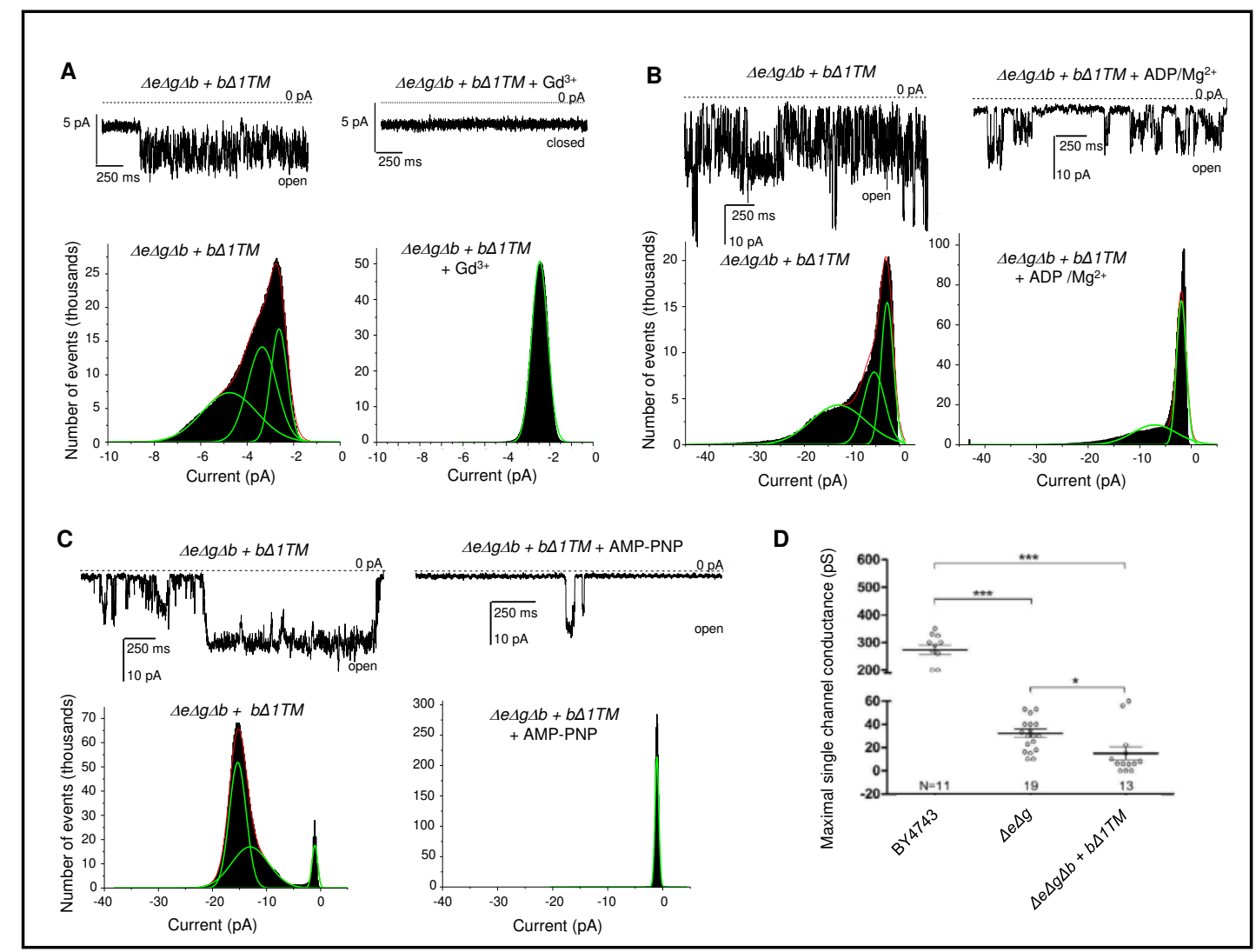

Fig. 5. Channel activity of $\Delta \mathrm{e} \Delta \mathrm{g} \Delta \mathrm{b}+\mathrm{b} \Delta 1 \mathrm{TM}$ F-ATP synthase dimers is characterized by low conductance and is sensitive to modulators of PTP. In all experiments $3 \mathrm{mM} \mathrm{Ca}^{2+}$ was added to the trans side and 100 $\mu \mathrm{M}$ phenylarsine oxide and $5 \mu \mathrm{M} \mathrm{Cu}(\mathrm{OP})_{2}$ to both the cis and trans side of the membrane. Except for panels $\mathrm{B}$ and $\mathrm{C}$, the concentration of $\mathrm{KCl}$ was $150 \mathrm{mM}$. (A) Conditions as in panel $4 \mathrm{D}$ for the $\Delta \mathrm{e} \Delta \mathrm{g} \Delta \mathrm{b}+\mathrm{b} \Delta 1 \mathrm{TM}$ F-ATP synthase dimers $(n=6)$. Representative current traces recorded at - $60 \mathrm{mV}$ Vcis and the corresponding amplitude histograms from $\geq 30$ s-long traces are shown. (B) Channel activity and amplitude histograms of $\Delta \mathrm{e} \Delta \mathrm{g} \Delta \mathrm{b}+\mathrm{b} \Delta 1 \mathrm{TM} F-A T P$ synthase dimers before (left panel) and after (right panel) addition of $1.6 \mathrm{mM} \mathrm{Mg}^{2+}$ and $2 \mathrm{mM}$ ADP to the trans side in $500 \mathrm{mM} \mathrm{KCl}$ (inhibition was observed in 4 out of 14 cases). Amplitude histograms were obtained as in panel b. Vcis $-40 \mathrm{mV}$. (C) Current traces of $\Delta \mathrm{e} \Delta \mathrm{g} \Delta \mathrm{b}+\mathrm{b} \Delta 1 \mathrm{TM}$ F-ATP synthase dimers recorded in $500 \mathrm{mM} \mathrm{KCl}$ and corresponding histograms before (left panel) and after (right panel) addition of $500 \mu \mathrm{M}$ AMP-PNP to the trans side (inhibition was observed in 3 out of 4 cases). Amplitude histograms are from $\geq 30$ s-long traces. Vcis $-20 \mathrm{mV}$. (D) Single channel maximal conductance defined for each experiment from amplitude histograms. When activity was characterized by very rapid transitions between closed and open states (flickering, e.g. Fig. 5C) current amplitude was measured manually and averaged $(n \geq 50)$ for each experiment. Maximal conductance observed in each experiment is reported as an individual dot on the graph. Mean \pm SEM values are indicated. ${ }^{* * *} \mathrm{P} \leq 0.01,{ }^{*} \mathrm{P} \leq 0.05$, Student's t-test.

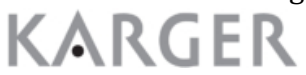




\section{Cellular Physiology Cell Physiol Biochem 2018;50:1840-1855

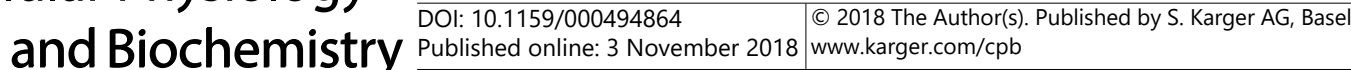 \\ Carraro et al.: Channel Formation by F-ATP Synthase e and g Subunits}

shown in Fig. 4D, n=19, sem). Channel activity showed complete block following addition of $\mathrm{Gd}^{3+}$ (Fig. 4D). The $\Delta e \Delta g$ channels displayed regular, long-lasting openings. Remarkably, the preparation from the $\Delta e \Delta g \Delta b+b \Delta 1 T M$ strain showed a prevalent flickering behavior with frequent transitions between the closed and open states, suggesting that the first TM segment of subunit $b$ has a stabilizing effect on the channel open state (Fig. $5 \mathrm{~A}$ and B). Also in this mutant the mean maximal conductance in $150 \mathrm{mM} \mathrm{KCl}$ was as low as $20.9 \pm 7.7 \mathrm{pS}(\mathrm{n}=12$, sem), channel activity being still blocked by $\mathrm{Gd}^{3+}$ (Fig. 5A). The channel was also sensitive to ADP $/ \mathrm{Mg}^{2+}$ (Fig. 5B) and to the non-hydrolyzable ATP analog AMP-PNP (Fig. 5C). Analysis of maximal conductance values from all experiments performed in $150 \mathrm{mM} \mathrm{KCl}$ documents the key importance of subunits e and $g$ in formation of the full-conductance PTP/MMC channel (Fig. 5D), while subunit b appears to stabilize the open state.

Taken together, the above findings suggest that the interface between $\mathrm{e}, \mathrm{g}$ and $\mathrm{b}$ subunits could be the site of $\mathrm{Ca}^{2+}$-dependent channel formation in yeast F-ATP synthase. To assess whether other proteins present in the preparations used for electrophysiology may be associated with the observed activity, mass spectrometry analysis was performed on the excised slices containing F-ATP synthase dimer bands of both wild-type and mutant strains (Tables S1 and S2 and Fig. S4C). This analysis revealed that many additional proteins could be detected (Table S1) including the adenine nucleotide translocator (ANT), the phosphate carrier (PiC) and mitochondrial porin (POR1, corresponding to mammalian VDAC). However, their relative amount was larger in the mutants that lack high-conductance channel openings. Thus, the large conductances observed in the wild-type strain cannot be assigned to ANT, PiC or VDAC.

\section{Discussion}

The findings of the present manuscript bear on the current debate on how the F-ATP synthase can form channels, and on whether the channel coincides with the PTP and its electrophysiological equivalent, the MMC. Genetic manipulation of specific components of F-ATP synthase has yielded apparently conflicting results on both issues. Consistent with a key role of F-ATP synthase in pore formation (i) partial knockdown of subunit c decreased PTP opening in permeabilized cells [50]; (ii) a T163S mutation on the F-ATP synthase $\beta$ subunit, which allows discrimination between $\mathrm{Ca}^{2+}$ and $\mathrm{Mg}^{2+}$ at the catalytic site [51], confers resistance to $\mathrm{Ca}^{2+}$-induced PTP opening and cell death [14]; (iii) H112Q and $\mathrm{H} 112 \mathrm{Y}$ mutations of OSCP subunit made the PTP/MMC totally refractory to inhibition by $\mathrm{H}^{+}$, the most effective PTP blockers [15]; and (iv) an R107A mutation of yeast subunit $\mathrm{g}$ completely blunted the effects of phenylglyoxal on the permeability transition [52]. On the other hand, genetic ablation of either the OSCP or b subunits [46] or of subunit c [53] led to the assembly of defective F-ATP synthase. Yet, upon cell permeabilization mitochondria underwent $\mathrm{CsA}$-sensitive $\mathrm{Ca}^{2+}$-induced $\mathrm{Ca}^{2+}$ release $[46,53]$ and cobalt-dependent quenching of mitochondrially-entrapped calcein [46], both events being consistent with occurrence of PTP opening. We have suggested that the apparent discrepancies can be explained when the pore size, rather than occurrence of PTP opening as such, is considered [47]. Indeed, PTP-dependent mitochondrial swelling in KCl-based media was drastically decreased in the OSCP- and b-null cells [46] indicating that the pore size was becoming close to the exclusion size for $\mathrm{K}^{+}$or $\mathrm{Cl}^{-}$. Our current findings indicate that ablation of the e and g subunits drastically decreases the high-conductance currents associated with the PTP/MMC, with persistence of low-conductance states that are influenced by deletion of the first TM $\alpha$-helix of subunit $b$.

The present data were obtained from preparations of F-ATP synthase eluted from native gels. In previous studies with a similar approach [2-5] strong support for assignment of the high-conductance channel activity to F-ATP synthase was provided by the pharmacological profile of PTP/MMC modulation, which included a variety of well-characterized PTP inhibitors and activators, including the highly selective OSCP ligand Bz423 [2, 16]. It is legitimate to ask, however, whether channel activity is also contributed by, or even due to, 


\section{Cellular Physiology Cell Physiol Biochem 2018;50:1840-1855

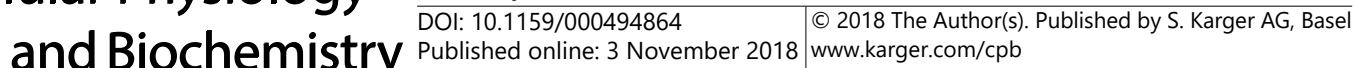 \\ Carraro et al.: Channel Formation by F-ATP Synthase e and g Subunits}

other proteins detected by mass spectrometry (Table S1 and Fig. S4C). Among these, ANT, PiC and VDAC deserve a special mention because they have been prime candidates for PTP formation, possibly through an interaction with the F-ATP synthase [54].

Partially purified ANT preparations displayed channel activity that resembles that of the bona fide PTP [55], yet genetic inactivation of both Ant isoforms in the mouse did not prevent $\mathrm{Ca}^{2+}$-dependent PTP formation and swelling in sucrose. The pore maintained sensitivity to key modulators except for the ANT inhibitor atractylate [56], suggesting that the ANT conformation/activity can affect the PTP sensitivity to $\mathrm{Ca}^{2+}$ but that ANT does not participate in channel formation. The contribution of VDAC and $\mathrm{PiC}$ has also been ruled out by genetic inactivation in mice and cells [57, 58] and in mouse hearts [59], respectively. Furthermore, ANT, PiC and VDAC were present in larger amounts in our deletion mutants that are totally devoid of MMC activity. This is an important point because the full conductance of VDAC is similar to that of the MMC $[60,61]$. On the other hand, in the presence of $\mathrm{Ca}^{2+}$ and $\mathrm{Mg}^{2+}$ the $\mathrm{PiC}$ from $S$. cerevisiae displays channel activity with mean conductance of only $25 \pm 5 \mathrm{pS}$ in $100 \mathrm{mM} \mathrm{KCl}$ [62]. Whether the low conductances we observe are due to substates of the $\mathrm{PTP} / \mathrm{MMC}$ or to the presence of the $\mathrm{PiC}$ remains an open question.

We would like to note that in $150 \mathrm{mM} \mathrm{KCl}$ the prevalent conductance of partially purified F-ATP synthases from different species ranges between a maximum of about 500 pS in mammals and a minimum of about $50 \mathrm{pS}$ in Drosophila, where the channel never displayed high-conductance openings [2-5]. Major species differences in F-ATP synthase primary structure are found in subunits e and g, which closely associate with the b subunit in a distinct lateral domain [10]. Although we cannot exclude that additional subunits may participate, our data suggest that these lateral domains could be the sites of $\mathrm{Ca}^{2+}$-dependent channel formation. We hope that high-resolution structures of the membrane domains of the enzyme will clarify the site and mechanism of pore formation.

\section{Acknowledgements}

We would to thank the electron microscopy facility of the Department of Biology, University of Padova. This work was funded by AIRC (IG17067 to P.B. and IG20286 to I.S.), Fondation Leducq (16CVD04 to P.B.) and HFSP RG0052 (to I.S.). We thank the Cassa di Risparmio di Padova e Rovigo (Cariparo) Holding for funding the acquisition of the LTQOrbitrao XL mass spectrometer.

\section{Disclosure Statement}

The authors declare no competing interests.

\section{References}

1 Bernardi P, Rasola A, Forte M, Lippe G: The Mitochondrial Permeability Transition Pore: Channel Formation by F-ATP Synthase, Integration in Signal Transduction, and Role in Pathophysiology. Physiol Rev 2015;95:1111-1155.

- Giorgio V, von Stockum S, Antoniel M, Fabbro A, Fogolari F, Forte M, Glick GD, Petronilli V, Zoratti M, Szabó I, Lippe G, Bernardi P: Dimers of mitochondrial ATP synthase form the permeability transition pore. Proc Natl Acad Sci U S A 2013;110:5887-5892.

-3 Alavian KN, Beutner G, Lazrove E, Sacchetti S, Park HA, Licznerski P, Li H, Nabili P, Hockensmith K, Graham $M$, Porter GA, Jr., Jonas EA: An uncoupling channel within the c-subunit ring of the $F_{1} F_{0}$ ATP synthase is the mitochondrial permeability transition pore. Proc Natl Acad Sci U S A 2014;111:10580-10585. 


\section{Cellular Physiology Cell Physiol Biochem 2018;50:1840-1855 \begin{tabular}{l|l|l|l|l} 
DOI: 10.1159/000494864 & (O)18 The Author(s). Published by S. Karger AG, Basel
\end{tabular} and Biochemistry Published online: 3 November 2018 www.karger.com/cpb

4 Carraro M, Giorgio V, Šileikyte J, Sartori G, Forte M, Lippe G, Zoratti M, Szabó I, Bernardi P: Channel Formation by Yeast F-ATP Synthase and the Role of Dimerization in the Mitochondrial Permeability Transition. J Biol Chem 2014;289:15980-15985.

5 von Stockum S, Giorgio V, Trevisan E, Lippe G, Glick GD, Forte MA, Da-Rè C, Checchetto V, Mazzotta G, Costa R, Szabò I, Bernardi P: F-ATPase of D. melanogaster Forms 53 Picosiemen (53-pS) Channels Responsible for Mitochondrial $\mathrm{Ca}^{2+}$-induced $\mathrm{Ca}^{2+}$ Release. J Biol Chem 2015;290:4537-4544.

6 Szabó I, Zoratti M: Mitochondrial channels: ion fluxes and more. Physiol Rev 2014;94:519-608.

-7 Baker LA, Watt IN, Runswick MJ, Walker JE, Rubinstein JL: Arrangement of subunits in intact mammalian mitochondrial ATP synthase determined by cryo-EM. Proc Natl Acad Sci U S A 2012;109:11675-11680.

-8 Zhou A, Rohou A, Schep DG, Bason JV, Montgomery MG, Walker JE, Grigorieff N, Rubinstein JL: Structure and conformational states of the bovine mitochondrial ATP synthase by cryo-EM. eLife Sciences 2015;4:e10180.

9 Hahn A, Parey K, Bublitz M, Mills DJ, Zickermann V, Vonck J, Kühlbrandt W, Meier T: Structure of a Complete ATP Synthase Dimer Reveals the Molecular Basis of Inner Mitochondrial Membrane Morphology. Mol Cell 2016;63:445-456.

10 Guo H, Bueler SA, Rubinstein JL: Atomic model for the dimeric $\mathrm{F}_{0}$ region of mitochondrial ATP synthase. Science 2017; eaao4815.

11 Srivastava AP, Luo M, Zhou W, Symersky J, Bai D, Chambers MG, Faraldo-Gomez JD, Liao M, Mueller DM: High-resolution cryo-EM analysis of the yeast ATP synthase in a lipid membrane. Science 2018;360:eaas9969.

12 Bernardi P, Vassanelli S, Veronese P, Colonna R, Szabó I, Zoratti M: Modulation of the mitochondrial permeability transition pore. Effect of protons and divalent cations. J Biol Chem 1992;267:2934-2939.

13 Szabó I, Bernardi P, Zoratti M: Modulation of the mitochondrial megachannel by divalent cations and protons. J Biol Chem 1992;267:2940-2946.

$>14$ Giorgio V, Burchell V, Schiavone M, Bassot C, Minervini G, Petronilli V, Argenton F, Forte M, Tosatto S, Lippe G, Bernardi P: $\mathrm{Ca}^{2+}$ binding to F-ATP synthase $\mathrm{b}$ subunit triggers the mitochondrial permeability transition. EMBO Rep 2017;18:1065-1076.

15 Antoniel M, Jones K, Antonucci S, Spolaore B, Fogolari F, Petronilli V, Giorgio V, Carraro M, Di Lisa F, Forte M, Szabó I, Lippe G, Bernardi P: The unique histidine in OSCP subunit of F-ATP synthase mediates inhibition of the permeability transition pore by acidic pH. EMBO Rep 2018;19:257-268.

16 Johnson KM, Chen X, Boitano A, Swenson L, Opipari AW, Jr., Glick GD: Identification and validation of the mitochondrial $\mathrm{F}_{1} \mathrm{~F}_{0}$-ATPase as the molecular target of the immunomodulatory benzodiazepine Bz-423. Chem Biol 2005;12:485-496.

17 Giorgio V, Guo L, Bassot C, Petronilli V, Bernardi P: Calcium and regulation of the mitochondrial permeability transition. Cell Calcium 2018;70:56-63.

18 Niedzwiecka K, Tisi R, Penna S, Lichocka M, Plochocka D, Kucharczyk R: Two mutations in mitochondrial ATP6 gene of ATP synthase, related to human cancer, affect ROS, calcium homeostasis and mitochondrial permeability transition in yeast. Biochim Biophys Acta 2018;1865:117-131.

19 Zeng X, Kucharczyk R, di Rago JP, Tzagoloff A: The leader peptide of yeast Atp6p is required for efficient interaction with the Atp9p ring of the mitochondrial ATPase. J Biol Chem 2007;282:36167-36176.

20 Steele DF, Butler CA, Fox TD: Expression of a recoded nuclear gene inserted into yeast mitochondrial DNA is limited by mRNA-specific translational activation. Proc Natl Acad Sci U S A 1996;93:5253-5257.

-21 Bonnefoy N, Fox TD: Genetic transformation of Saccharomyces cerevisiae mitochondria. Methods Cell Biol 2001;65:381-396.

22 Rak M, Tetaud E, Godard F, Sagot I, Salin B, Duvezin-Caubet S, Slonimski PP, Rytka J, di Rago JP: Yeast cells lacking the mitochondrial gene encoding the ATP synthase subunit 6 exhibit a selective loss of complex IV and unusual mitochondrial morphology. J Biol Chem 2007;282:10853-10864.

23 Unger AK, Geimer S, Harner M, Neupert W, Westermann B: Analysis of Yeast Mitochondria by Electron Microscopy. Methods Mol Biol 2017;1567:293-314.

24 Arrigoni G, Pagano MA, Sarno S, Cesaro L, James P, Pinna LA: Mass spectrometry analysis of a protein kinase CK2beta subunit interactome isolated from mouse brain by affinity chromatography. J Proteome Res 2008;7:990-1000.

-25 Cox J, Mann M: MaxQuant enables high peptide identification rates, individualized p.p.b.-range mass accuracies and proteome-wide protein quantification. Nat Biotechnol 2008;26:1367-1372. 


\section{Cellular Physiology Cell Physiol Biochem 2018;50:1840-1855 \begin{tabular}{l|l|l|l|} 
DOI: 10.1159/000494864 2018 The Author(s). Published by S. Karger AG, Basel \\
\hline
\end{tabular} and Biochemistry Published online: 3 November 2018 www.karger.com/cpb

26 Cox J, Neuhauser N, Michalski A, Scheltema RA, Olsen JV, Mann M: Andromeda: a peptide search engine integrated into the MaxQuant environment. J Proteome Res 2011;10:1794-1805.

-27 Schwanhausser B, Busse D, Li N, Dittmar G, Schuchhardt J, Wolf J, Chen W, Selbach M: Global quantification of mammalian gene expression control. Nature 2011;473:337-342.

28 The UniProt Consortium: UniProt: the universal protein knowledgebase. Nucleic Acids Res 2018;46:2699.

-29 Schneider A, Dessimoz C, Gonnet GH: OMA Browser--exploring orthologous relations across 352 complete genomes. Bioinformatics 2007;23:2180-2182.

30 Notredame C, Higgins DG, Heringa J: T-Coffee: A novel method for fast and accurate multiple sequence alignment. J Mol Biol 2000;302:205-217.

-31 Waterhouse AM, Procter JB, Martin DM, Clamp M, Barton GJ: Jalview Version 2--a multiple sequence alignment editor and analysis workbench. Bioinformatics 2009;25:1189-1191.

-32 Finn RD, Coggill P, Eberhardt RY, Eddy SR, Mistry J, Mitchell AL, Potter SC, Punta M, Qureshi M, SangradorVegas A, Salazar GA, Tate J, Bateman A: The Pfam protein families database: towards a more sustainable future. Nucleic Acids Res 2016;44:D279-D285.

33 Piovesan D, Walsh I, Minervini G, Tosatto SCE: FELLS: fast estimator of latent local structure. Bioinformatics 2017;33:1889-1891.

34 Krogh A, Larsson B, von Heijne G, Sonnhammer EL: Predicting transmembrane protein topology with a hidden Markov model: application to complete genomes. J Mol Biol 2001;305:567-580.

-35 Pettersen EF, Goddard TD, Huang CC, Couch GS, Greenblatt DM, Meng EC, Ferrin TE: UCSF Chimera--a visualization system for exploratory research and analysis. J Comput Chem 2004;25:1605-1612.

-36 Spannagel C, Vaillier J, Arselin G, Graves PV, Grandier-Vazeille X, Velours J: Evidence of a subunit 4 (subunit b) dimer in favor of the proximity of ATP synthase complexes in yeast inner mitochondrial membrane. Biochim Biophys Acta 1998;1414:260-264.

37 Soubannier V, Vaillier J, Paumard P, Coulary B, Schaeffer J, Velours J: In the absence of the first membranespanning segment of subunit $4(\mathrm{~b})$, the yeast ATP synthase is functional but does not dimerize or oligomerize. J Biol Chem 2002;277:10739-10745.

-38 Arselin G, Giraud MF, Dautant A, Vaillier J, Brèthes D, Coulary-Salin B, Schaeffer J, Velours J: The GxxxG motif of the transmembrane domain of subunit e is involved in the dimerization/oligomerization of the yeast ATP synthase complex in the mitochondrial membrane. Eur J Biochem 2003;270:1875-1884.

39 Bustos DM, Velours J: The modification of the conserved GXXXG motif of the membrane-spanning segment of subunit g destabilizes the supramolecular species of yeast ATP synthase. J Biol Chem 2005;280:2900429010.

40 Fronzes R, Weimann T, Vaillier J, Velours J, Brèthes D: The peripheral stalk participates in the yeast ATP synthase dimerization independently of e and g subunits. Biochemistry 2006;45:6715-6723.

41 Wittig I, Velours J, Stuart R, Schägger H: Characterization of domain interfaces in monomeric and dimeric ATP synthase. Mol Cell Proteomics 2008;7:995-1004.

-42 Arnold I, Pfeiffer K, Neupert W, Stuart RA, Schägger H: Yeast mitochondrial $\mathrm{F}_{1} \mathrm{~F}_{0}$-ATP synthase exists as a dimer: identification of three dimer-specific subunits. EMBO J 1998;17:7170-7178.

-43 Arselin G, Vaillier J, Salin B, Schaeffer J, Giraud MF, Dautant A, Brèthes D, Velours J: The modulation in subunits e and g amounts of yeast ATP synthase modifies mitochondrial cristae morphology. J Biol Chem 2004;279:40392-40399.

-44 Davies KM, Anselmi C, Wittig I, Faraldo-Gomez JD, Kühlbrandt W: Structure of the yeast $\mathrm{F}_{1} \mathrm{~F}_{0}$-ATP synthase dimer and its role in shaping the mitochondrial cristae. Proc Natl Acad Sci U S A 2012;109:13602-13607.

-45 Velours J, Stines-Chaumeil C, Habersetzer J, Chaignepain S, Dautant A, Brèthes D: Evidence of the proximity of ATP synthase subunits 6 (a) in the inner mitochondrial membrane and in the supramolecular forms of Saccharomyces cerevisiae ATP synthase. J Biol Chem 2011;286:35477-35484.

46 He J, Carroll J, Ding S, Fearnley IM, Walker JE: Permeability transition in human mitochondria persists in the absence of peripheral stalk subunits of ATP synthase. Proc Natl Acad Sci U S A 2017;114:9086-9091.

47 Bernardi P, Lippe G: Channel Formation by F-ATP Synthase and the Permeability Transition Pore: An Update. Curr Opin Physiol 2018;3:1-5.

48 Carraro M, Bernardi P: Calcium and reactive oxygen species in regulation of the mitochondrial permeability transition and of programmed cell death in yeast. Cell Calcium 2016;60:102-107. 


\section{Cellular Physiology Cell Physiol Biochem 2018;50:1840-1855

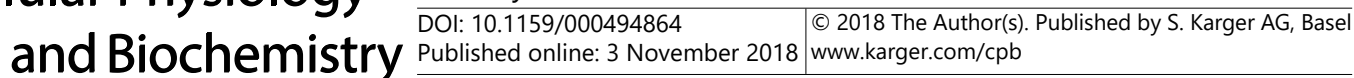

49 Rehling P, Model K, Brandner K, Kovermann P, Sickmann A, Meyer HE, Kühlbrandt W, Wagner R, Truscott KN, Pfanner N: Protein insertion into the mitochondrial inner membrane by a twin-pore translocase. Science 2003;299:1747-1751.

50 Bonora M, Bononi A, De Marchi E, Giorgi C, Lebiedzinska M, Marchi S, Patergnani S, Rimessi A, Suski JM, Wojtala A, Wieckowski MR, Kroemer G, Galluzzi L, Pinton P: Role of the c subunit of the $F_{0}$ ATP synthase in mitochondrial permeability transition. Cell Cycle 2013;12:674-683.

-51 Nathanson L, Gromet-Elhanan Z: Mutations in the b-subunit $\mathrm{Thr}^{159}$ and Glu ${ }^{184}$ of the Rhodospirillum rubrum $\mathrm{F}_{0} \mathrm{~F}_{1}$ ATP synthase reveal differences in ligands for the coupled $\mathrm{Mg}^{2+}$ - and decoupled $\mathrm{Ca}^{2+}$-dependent $\mathrm{F}_{0} \mathrm{~F}_{1}$ activities. J Biol Chem 2000;275:901-905.

52 Guo L, Carraro M, Sartori G, Minervini G, Eriksson 0, Petronilli V, Bernardi P: Arginine 107 of yeast ATP synthase subunit g mediates sensitivity of the mitochondrial permeability transition to phenylglyoxal. J Biol Chem 2018;293:14632-14645.

-53 He J, Ford HC, Carroll J, Ding S, Fearnley IM, Walker JE: Persistence of the mitochondrial permeability transition in the absence of subunit c of human ATP synthase. Proc Natl Acad Sci U S A 2017;114:3409. 3414 .

54 Halestrap AP, Richardson AP: The mitochondrial permeability transition: A current perspective on its identity and role in ischaemia/reperfusion injury. J Mol Cell Cardiol 2015;78:129-141.

55 Brustovetsky N, Klingenberg M: Mitochondrial ADP/ATP carrier can be reversibly converted into a large channel by $\mathrm{Ca}^{2+}$. Biochemistry 1996;35:8483-8488.

56 Kokoszka JE, Waymire KG, Levy SE, Sligh JE, Cai J, Jones DP, MacGregor GR, Wallace DC: The ADP/ATP translocator is not essential for the mitochondrial permeability transition pore. Nature 2004;427:461-465.

57 Krauskopf A, Eriksson 0, Craigen WJ, Forte MA, Bernardi P: Properties of the permeability transition in VDAC1\% mitochondria. Biochim Biophys Acta 2006;1757:590-595.

58 Baines CP, Kaiser RA, Sheiko T, Craigen WJ, Molkentin JD: Voltage-dependent anion channels are dispensable for mitochondrial-dependent cell death. Nat Cell Biol 2007;9:550-555.

59 Gutierrez-Aguilar M, Douglas DL, Gibson AK, Domeier TL, Molkentin JD, Baines CP: Genetic manipulation of the cardiac mitochondrial phosphate carrier does not affect permeability transition. J Mol Cell Cardiol 2014;72:316-325.

60 Magri A, Reina S, De P, V: VDAC1 as Pharmacological Target in Cancer and Neurodegeneration: Focus on Its Role in Apoptosis. Front Chem 2018;6:108.

61 Checchetto V, Reina S, Magri A, Szabò I, De Pinto V: Recombinant human voltage dependent anion selective channel isoform 3 (hVDAC3) forms pores with a very small conductance. Cell Physiol Biochem 2014;34:842-853.

62 Herick K, Krämer R, Lühring H: Patch clamp investigation into the phosphate carrier from Saccharomyces cerevisiae mitochondria. Biochim Biophys Acta 1997;1321:207-220. 